\title{
SPEKTRUM INDUSTRI
}

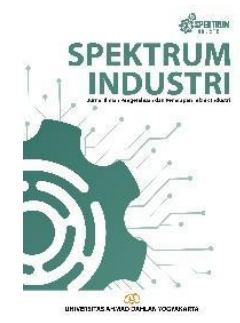

\section{LABORATORY STUDY OF POLYPROPYLENE-BASED HONEYCOMB CORE FOR SANDWICH COMPOSITES}

\author{
Karunamit Saensuriwong ${ }^{1,}$, , Thongchart Kerdphol' ${ }^{2}$, and Veena Phunpeng ${ }^{1}$ \\ ${ }^{1}$ Faculty of Engineering, School of Mechanical Engineering, Suranaree University of Technology \\ 111, Maha Witthayalai Rd., Suranaree, Mueang Nakhon Ratchasima District, Nakhon Ratchasima, 30000, Thailand \\ ${ }^{2}$ Faculty of Engineering, Department of Electrical Engineering and Electronics, Kyushu Institute of Technology \\ 1-1, Sensui-cho, Tobata-ku, Kitakyushu-shi, Fukuoka, 804-8550, Japan
}

\begin{tabular}{l}
\hline ARTICLE INFO \\
\hline Article history: \\
Received : August 2021 \\
Accepted : October 2021 \\
\\
\hline Keywords: \\
Carbon fiber \\
Glass fiber \\
Polypropylene (PP) \\
Sandwich composites
\end{tabular}

\section{INTRODUCTION}

Composite materials are the combination of two materials, such as fiber and matrix with varying physical and chemical properties. According to Bhagwan et al. (1980), Salernitano et al. (2003), and Cho et al. (2007), composite materials are increasingly used in different applications such as aerospace components, automotive, construction, etc. The mechanical and thermal properties of composite materials are strengthened by matrix epoxy reinforcement (Cho et al. 2007, Gary et al. 1993, Jagannatha et al. 2015, James et al. 1989, Shang Han et al. 2001,

\footnotetext{
* Corresponding author

E-mail address: karunamitsaen@gmail.com

https://doi.org/10.12928/si.v19i2.21659
}

\begin{abstract}
The polypropylene-based honeycomb core is one of the most of sandwich composites. This material is widely used in various science, technology, and engineering fields, including aerospace applications, due to its high strength properties. Therefore, this research evaluated the mechanical properties of the well-known hybrid composites of carbon fiber $(C F)$ and glass fiber $(G F)$ under reinforced sandwich composites. The different curingpressure values of each material were analyzed to determine the pressure responsible for the superior performances and properties. The specimens were moulded using the hand lay-up or cloth laying angle technique of the carbon fiber. Furthermore, by changing direction, the greatest load-bearing direction based on the bending test was determined. According to the ASTM standard on strength determination, an increase in curing pressure leads to a rise in flexural stress. By placing the material orientation in the right order (i.e., [CF90/CFO/GFO/Core/GFO/ GFo]) the highest strength is obtained. However, when the followed its maximum value, the fracture of the specimen, results showed that the lower the curing pressure, the thicker the workpiece decreased fiber volume fraction. The results also showed that changes in the curing pressure and laying angle affect the mechanical properties of the sandwich composites.
\end{abstract}


Mohd Zulfli et al. 2013). The most popular type of fibers used in this type of material is carbon because it is strong, lightweight, heat resistant, with high mechanical properties (Cho et al., 2007; Gary et al., 1993; Jagannatha et al., 2015; James, 1989). The other popular type is glass fiber, which comprises strong materials in terms of ductility and toughness (Shang Han et al. 2001, Mohd Zulfli et al. 2013, Masahiro et al. 2013). The strength of composite materials is dependent on multiple parameters, such as the number of layers of fabrics, ply orientation, fiber and matrix types, which also affect the mechanical properties (Masahiro et al. 2013, Hossein et al. 2014). Woven fabric is made by interlacing fibers at right angles, and this works by overlapping pieces of material work together. Therefore, the fiber placement characteristics affect the mechanical properties (Neumeister et al. 1996).

Sandwich composite materials indicate a specific material with high mechanical properties. Therefore, to provide a wide range of potential applications, hybrid composite and core are embedded. Sezgin et al. (2010) and Riccio et al. (2016) stated that sandwich plates/panels with polypropylene cores lead to higher load subjection, which also affects the mechanical properties of the composite material. According to preliminary studies, many variables affect the pressure, temperature, and forming methods (Fuda et al., 2017; Ghasemi et al., 2016; Hoda et al., 2015; Sungho et al. 2011).

Therefore, this laboratory/experimental study examined the use of epoxy resin as the link between carbon and glass fibers, matrix, and core. Each specimen applied different pressure and curing processes with the bending test used to determine the mechanical properties of the materials. The curing pressure variations are set at the constant heat in all experiments to analyze the changes in mechanical properties properly.

\section{RESEARCH METHOD Material Preparation}

Carbon Fiber (CF) fabric 3K, 1 x 1 plain weave with $200 \mathrm{~g} / \mathrm{m}^{3}$ was used for the fabrication of sandwich composite materials. Meanwhile, the glass fiber (GF) 1 x 1 plain weave with $80 \mathrm{~g} / \mathrm{m}^{3}$, Epoxy resin (manufactured number: ER550) shown in Figure 1(a), and polypropylene-based honeycomb core (PP-core) were used to prepare the sandwich panels. The internal structure in Figure 1(a) is the fiber orientation in the fabric orientation at an angle of $0^{0}$ before it is laid as a laminate, as illustrated in Figure 1(b). The mechanical properties of carbon and glass fiber are shown in Table 1.

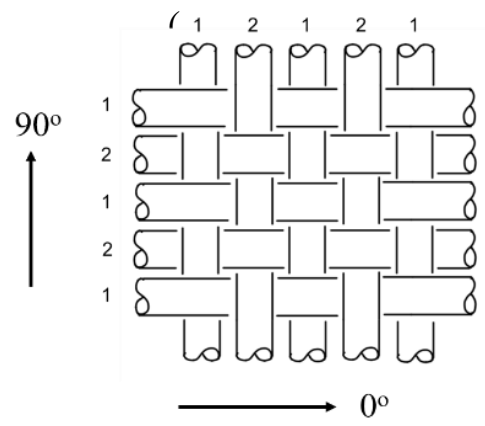

(a)

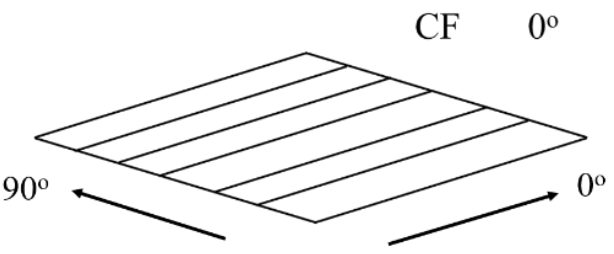

(b)

Figure 1: (a) The actual structure of carbon fiber and glass fiber with a $1 \times 1$ plain weave and b) an idealized structure at angle $0^{0}$ 
Table 1: Mechanical properties of carbon fiber and glass fiber

\begin{tabular}{lcc}
\hline \multicolumn{1}{c}{ Fiber type } & Density $\left(\mathbf{g} / \mathbf{c m}^{\mathbf{3}}\right)$ & Tensile strength $(\mathbf{G P a})$ \\
\hline Carbon fiber $^{\mathrm{a}}$ & 1.8 & 3.4 \\
Glass fiber $^{\mathrm{b}}$ & 1.2 & 0.795 \\
\hline
\end{tabular}

a. (Torayca Innovation by Chemistry, 1999)

b. (Compositesplaza, 2013)

(a)

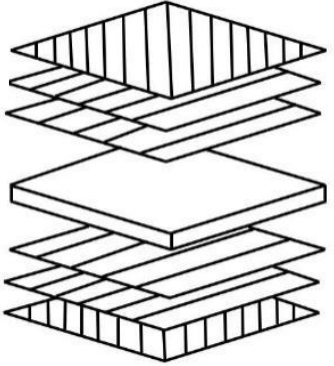

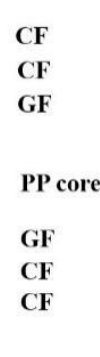

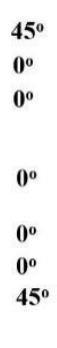

(b)

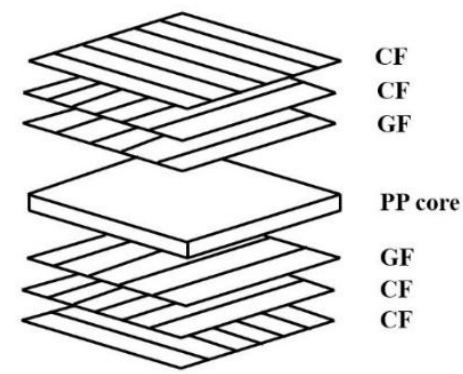

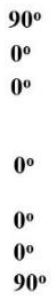

Figure 2: Stacking sequence of symmetric composite laminates (a) $[45 \% \% \% \% \% \% \%$ (b) $\left[90^{\circ} / 0^{\circ} / 0^{\circ} / 0^{\circ} / 0^{\circ} / 0^{\circ} / 90^{\circ}\right]$.

\section{Experimental Preparation}

The experimental process used to prepare carbon fiber is properly cut into 2 pieces at $45^{\circ}$ and $0^{0}\left(20 \times 20 \mathrm{~cm}^{2}\right)$. Meanwhile, the prepared glass fiber and PP-based honeycomb core are cut into 2 and 1 pieces (size: $20 \times 20 \mathrm{~cm}^{2}$ ). In addition, the epoxy resin is produced by mixing substances PP-based honeycomb core, carbon, and glass fibers using a mixing ratio (MR) of 100:35, as shown in Figure 2. This process is known as the hand lay-up process. Sandwich structures are impregnated and laminated by the hand lay-up technique based on the aluminum mold for different materials stack sequence of $[\mathrm{CF} / \mathrm{CF} / \mathrm{GF} / \mathrm{PP}$-core/GF/CF/CF] by different ply orientation patterns between $\left[45^{\circ} / 0^{\circ} / 0^{\circ} / 0^{\circ} / 0^{\circ} / 0^{\circ} / 45^{\circ}\right]$ and $\left[90^{\circ} / 0^{\circ} / 0^{\circ} / 0^{\circ} / 0^{\circ} / 0^{\circ} / 90^{\circ}\right]$. The ply orientation of $0^{0}$ and $45^{\circ}$ are shown in Figure 3. After the hand lay-up process, the sandwich panels are placed in an oven under the curing condition, as shown in Table 2. During the curing process, the sandwich panels are connected to a vacuum pump to eliminate air bubbles. The mechanical properties are investigated under the variation of the curing pressure with a temperature profile under constant pressure, as shown in Figure 4.

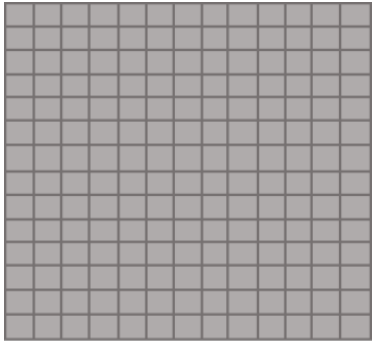

(a)

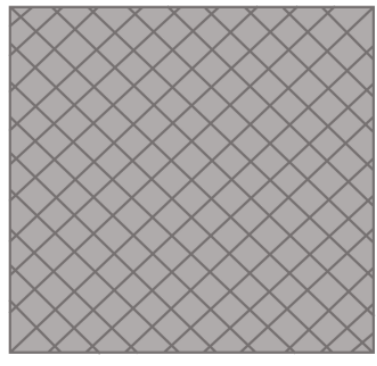

(b)

Figure 3: An actual ply orientation of (a) $0^{\circ}$ and (b) $45^{\circ}$ 
Table 2: Designed cure cycle for experimental study

\begin{tabular}{cccc}
\hline $\begin{array}{c}\text { Number } \\
\text { of } \\
\text { specimens }\end{array}$ & $\begin{array}{c}\text { Temperature } \\
\left({ }^{\circ} \mathrm{C}\right)\end{array}$ & $\begin{array}{c}\text { Cure vacuum } \\
\text { pressure } \\
\text { (bar) }\end{array}$ & $\begin{array}{c}\text { Ply orientation in sandwich } \\
\text { composites by hand lay-up } \\
\text { [CF/CF/GF/PP- } \\
\text { core/GF/CF/CF] }\end{array}$ \\
\hline 1 & 100 & -0.8 & {$\left[45^{\circ} / 0^{\circ} / 0^{\circ} / 0^{\circ} / 0^{\circ} / 0^{\circ} / 45^{\circ}\right]$} \\
2 & 100 & -0.4 & {$\left[45^{\circ} / 0^{\circ} / 0^{\circ} / 0^{\circ} / 0^{\circ} / 0^{\circ} / 45^{\circ}\right]$} \\
3 & 100 & 0 & {$\left[45^{\circ} / 0^{\circ} / 0^{\circ} / 0^{\circ} / 0^{\circ} / 0^{\circ} / 45^{\circ}\right]$} \\
4 & 100 & -0.8 & {$\left[90 \% 0^{\circ} / 0^{\circ} / 0^{\circ} / 0^{\circ} / 0^{\circ} / 90^{\circ}\right]$} \\
5 & 100 & -0.4 & {$\left[90 \% 0^{\circ} / 0^{\circ} / 0^{\circ} / 0^{\circ} / 90^{\circ}\right]$} \\
6 & 100 & 0 & {$\left[90 \% 0^{\circ} / 0^{\circ} / 0^{\circ} / 0^{\circ} / 0^{\circ} / 90^{\circ}\right]$} \\
\hline
\end{tabular}

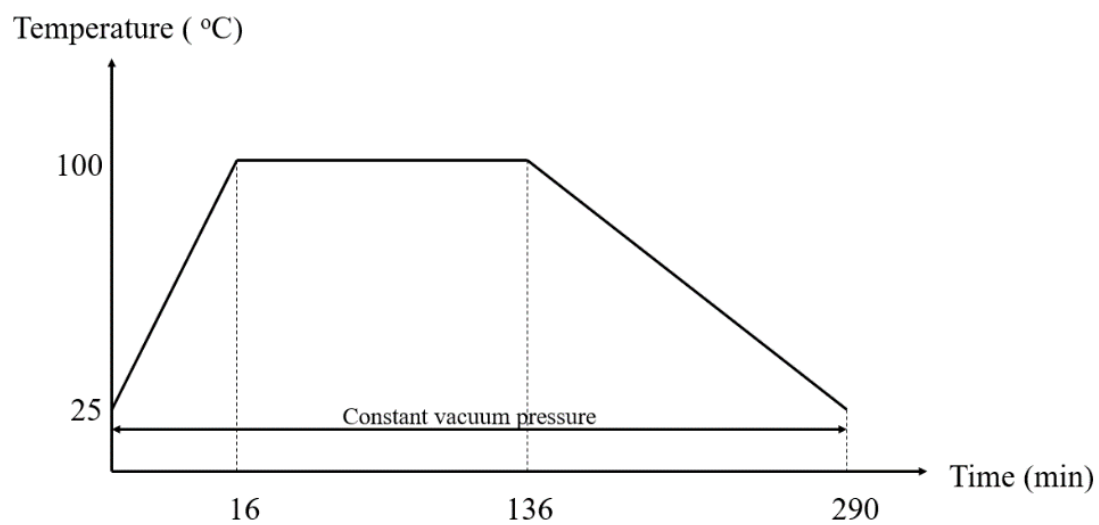

Figure 4: Temperature profile under constant vacuum pressure.

\section{Bending Testing}

The bending testing technique is used to investigate the change in curing conditions, which led to specimen failure. The flexural test is performed under three-point bending mode with the specimen dimension of $191 \times 20 \times 7.2 \mathrm{~mm}^{3}$ shown in Figure 5. This is in accordance with the standard of ASTM D790M-03 with the crosshead speed of $1.2 \mathrm{~mm} / \mathrm{min}$ and supported span length of $100 \mathrm{~mm}$ by using the universal testing machine (UTM) - $100 \mathrm{kN}$.

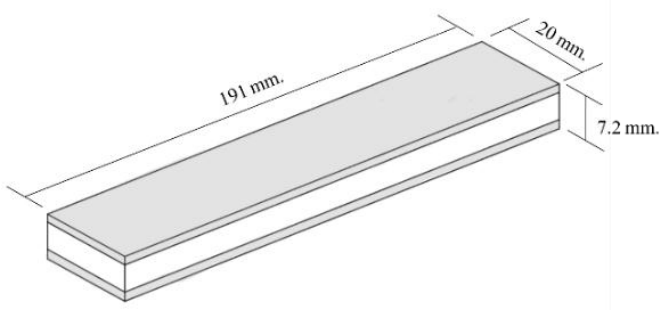

(a)

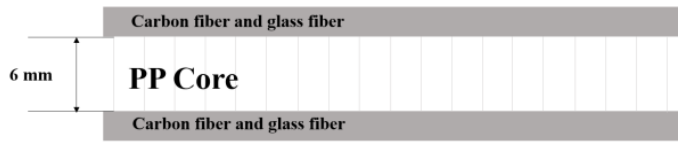

(b)

Figure 5: The bending test specimen; (a) dimension of a specimen and (b) right side of the specimen. 


\section{RESULTS AND DISCUSSION}

Specimens 1 to 6 showed varying deflections when subjected to bending loads. This was observed under the consideration of the vacuum pressure process and directions of angleply lamination. Furthermore, the lower the vacuum pressure, the better the flexural strength and capability of materials subjected to the flexural deformation. However, the materials seem to be more conserved from the deflection because the lower the vacuum pressure, the greater the bonds between the fiber, matrix, and PP-core with a less porous matrix. Moreover, the composite laminated ply orientations played a significant role in the flexural stress and load applied to the materials. The composite laminated in the ply orientation of $\left[90 \% 0^{\circ} / 0^{\circ} / 0^{\circ} / 0^{\circ} / 0^{\circ} / 90^{\circ}\right]$ showed better results than $\left[45^{\circ} / 0^{\circ} / 0^{\circ} / 0^{\circ} / 0^{\circ} / 0^{\circ} / 45^{\circ}\right]$ in Figures 6 and 7. Furthermore, the ply is subjected to the axial load along the length of the fiber when the force is applied at $90^{\circ}$ of ply orientations, in which the advantage of the reinforcement fiber to subjected to the axial load.

In the laboratory study, it was noticed that the lower the vacuum pressure, the thinner the layer of the composite laminates in accordance with the curing pressure. The specimen is compressed when it is subjected to pressure, thereby leading to a decrease in the air gap and thickness. It is a perfect bonding between layers and also enables proper lamination when the vacuum pump is set at higher pressure during the curing process. The increased vacuum pressure leads to increased matrix because vacuum pressure affects thickness and flexural strength, such as fiber, coordination, and epoxy resin adsorption. The specimen strength lowers the deformation and is more difficult to fracture, as shown in Figure 8. The ply-orientation laminated affects the flexural stress performed on the specimen by $45^{0}$ less than the $90{ }^{0}$ as shown in Figure 9.

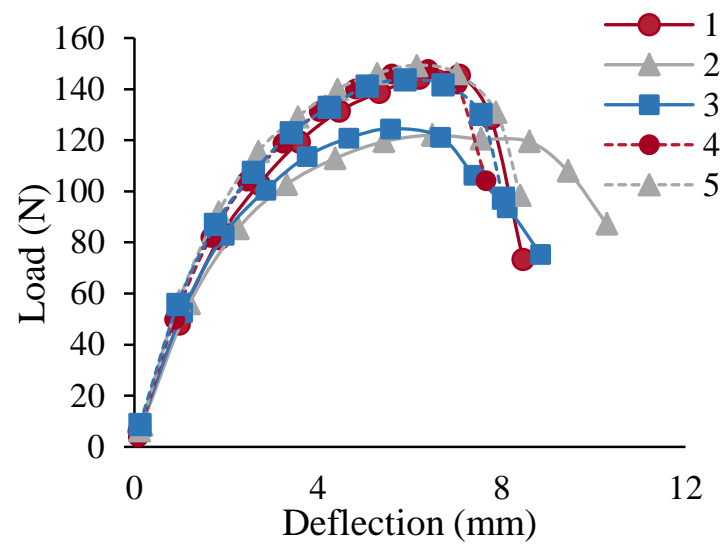

Figure 6: The relationship between applied loads and deflections.

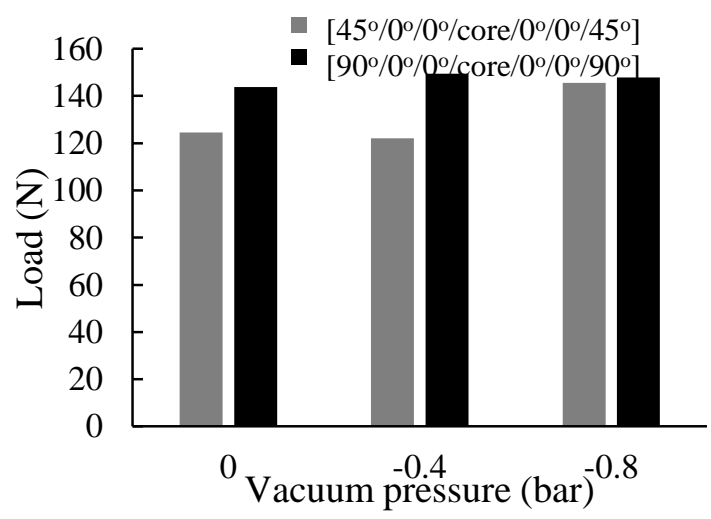

Figure 7: Effect of vacuum pressure and ply orientations of sandwich composites subjected to loads. 


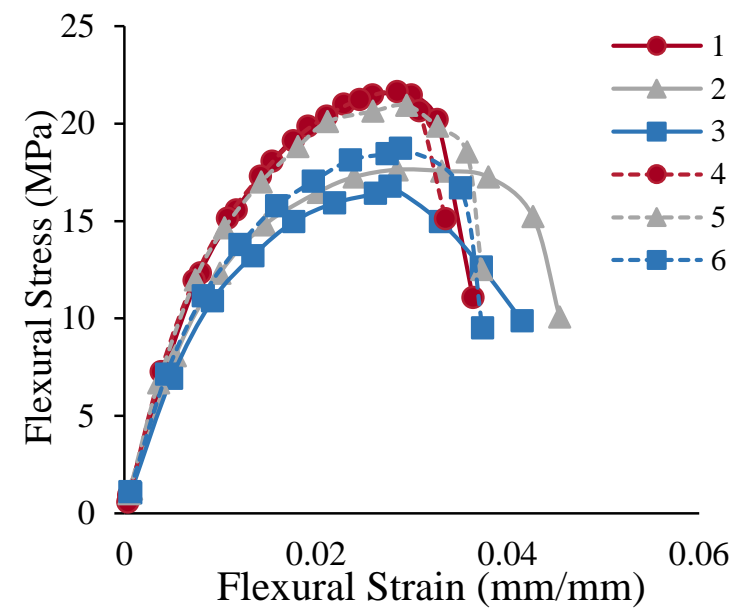

Figure 8: The flexural stress and flexural strain curve of the sandwich composites.

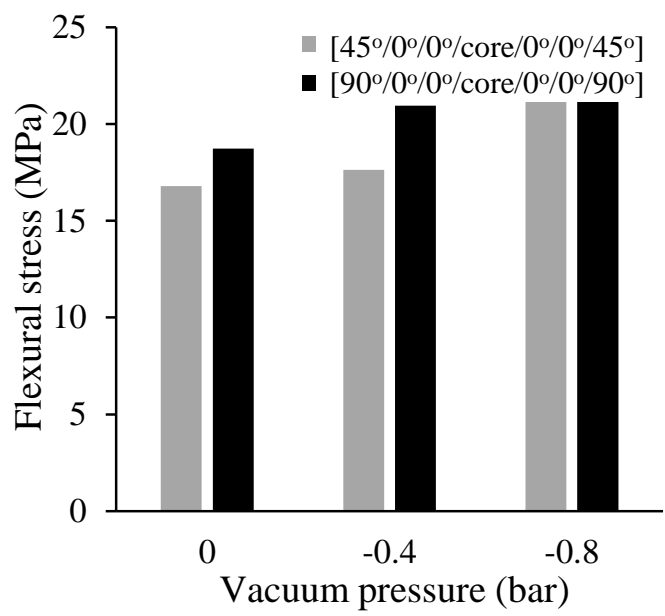

Figure 9: Effect of vacuum pressure and ply orientations of sandwich composites on the flexural stress.

According to the bending test, the force acting on the specimen causes fracture failure, and the characteristics of each type of ply orientation are shown in Figure 10. The results obtained from 2 types of ply orientation showed that the crack propagation is generally followed the fabric's fiber orientation.

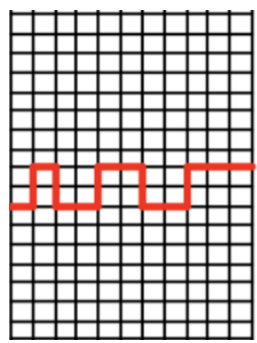

(a)

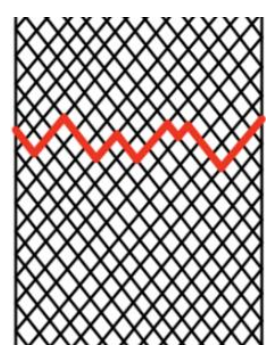

(b)

Figure 10: Schematic illustrations of bending fracture model for (a) $0^{\circ} / 90^{\circ}$ and (b) $45^{\circ} /-45^{\circ}$ 


\section{CONCLUSIONS}

The variation of curing pressure plays a crucial role in the mechanical property and the ply orientation of sandwich panels. Meanwhile, the vacuum pressure and ply-orientation affect the mechanical properties of the manufacturing process. An increase in the load and flexural stress leads to a decrease in vacuum pressure by -0.8 bar, which is the strongest determinant of the thickness of the specimen. Furthermore, when the thickness of the specimen is lower, the strength and bonding between the fiber and the matrix are improved. The stacking sequence and ply-orientation of composite laminates show a significant role in the mechanical property and the manufacturing process. A change in orientation subjects the capability of the sandwich composites to load and flexural stress. It also affects the fracture characteristics of the laminate. The laminations at $90^{\circ}$ subject the specimen to better axial loads compared to $45^{\circ}$.

\section{REFERENCES}

ASTM. (1970). D790-03. Standard test methods for flexural properties of unreinforced and reinforced plastics and electrical insulating materials. West Conshohocken: ASTM Int'1.

Bhagwan, D., Lawrence, J. (1980). Analysis and Performance of Fiber Composites. Mechanics of Composite Materials, 48, 213.

Cho, J., Chen, J., Daniel. I.M. (2007). Mechanical enhancement of carbon fiber/epoxy composites by graphite nanoplatelet reinforcement. Scripta Materialia, 56, 685-688.

Compositesplaza. (2013). EGWFPL080-100. Technical datasheet. Netherlands: Compositesplaza BV.

Fuda, N., Weilong. C., Yingbin, H., Hui, W. (2017). Additive manufacturing of carbon-fiberreinforced plastic composites using fused deposition modeling: Effects of process parameters on tensile properties. Composites Material, 51(4), 451-462.

Gary, G.T., Gary, L.D., Daniel, W.G., Jerome, J.M., Thomas, A.P., Cameron, J.D., Michael, J.B. (1993). Physical properties of vapor-grown carbon fibers. Carbon, 31(7), 1039-1047.

Ghasemi, R.A., Moradi, M. (2016). Low thermal cycling effects on mechanical properties of laminated composite materials. Mechanics of Materials, 96, 126-137.

Masahiro, H., Takashi, I. (2013). Effect of Carbon Fiber Orientation and Helix Angle on CFRP Cutting Characteristics by End-Milling. Automation Technology, 7(3), 292-299.

Hoda, K., Seyed, A.S., Bob, M., Melanie, V. (2015) Effects of variation in autoclave pressure, temperature, and vacuum-application time on porosity and mechanical properties of a carbon fiber/epoxy composite. Composites Material. 46(16),1985-2004.

Jagannatha, D.T., Harish, G. (2015). Mechanical properties of carbon/glass fiber reinforced epoxy hybrid polymer composites. International Journal of Mechanical Engineering and Robotics Research, 4(2), 131-137.

James, E.S. (1989). Oxidation protection for carbon fiber composites. Carbon, 27(5), 709-715.

Mohd Zulfli, H.N., Abu Bakar, A., Chow, S.W. (2013). Mechanical and thermal properties improvement of nano calcium carbonate-filled epoxy/glass fiber composite laminates. High Performance Polymer, 26(2), 223-229.

Neumeister, J., Jansson, S., Leckie, F. (1996). The effect of fiber architecture on the mechanical properties of carbon/carbon fiber composites. Mechanical properties of composites, 44(2), 573-585.

Hossein, R., Heydar Mahmoudi, N.S., Shohreh, S.M., Alireza A. (2014). Mechanical Properties of Carbon Fiber/Epoxy Composites: Effects of Number of Plies, Fiber Contents, and Angle-Ply Layers. Polymer Engineering and Science, 54(11), 2676-2682.

Riccio, A., Raimondo, A., Sellitto, A., Acanfora, V., Zarrelli, M. (2016). Multifunctional Polypropylene Core for Aerospace Sandwich Composite Panels. Procedia Engineering, 167, 64-70.

Salernitano, E., Migliaresi, C. (2003). Composite materials for biomedical applications: a review. Biomaterials \& Biomechanics, 1(1), 3-18. 
Sezgin, E.F., Tanglu, M. (2010). Mechanical Behavior of Polypropylene-based Honeycomb-Core Composite Sandwich Structures. Reinforced Plastics and Composites, 29(10), 1569-1579.

Shang Han, W., Feng Yih W., Chen Chi, M., Wen Chi, C., Chun Ting K., Hsu Chiang, K. and Wei Jen, C. (2001). Mechanical, thermal and morphological properties of glass fiber and carbon fiber reinforced polyamide- 6 and polyamide-6rclay nanocomposites. Material Letters, 49, 327-333.

Sungho, L., Jihoon, K., Bon Cheol, K., Junkyong, K., Yongsik, C. (2011). Effect of Process Condition on Tensile Properties of Carbon Fiber. Carbon Letters, 12(1), 26-30.

Torayca Innovation by Chemistry. (1999). UT70-20G. High performance carbon fiber Torayca. Tokyo: Toray Industries,Inc. 